九州大学学術情報リポジトリ

Kyushu University Institutional Repository

\title{
Performance Evaluation of Wind Decontamination System by Computational Fluid Dynamics
}

\section{$\mathrm{Li}$, Cong}

Faculty of Marine and Civil Engineering, Dalian Ocean University Interdisciplinary Graduate School of Engineering Sciences, Kyushu University

Ito, Kazuhide

Interdisciplinary Graduate School of Engineering Sciences, Kyushu University

https://doi.org/10.5109/1495158

出版情報：Evergreen. 1 (2)，pp.12-17，2014-09. Green Asia Education Center バージョン：

権利関係 : 


\title{
Performance Evaluation of Wind Decontamination System by Computational Fluid Dynamics
}

\author{
Cong $\mathrm{Li}^{1,2}$, Kazuhide $\mathrm{Ito}^{2 *}$ \\ ${ }^{1}$ Faculty of Marine and Civil Engineering, Dalian Ocean University, China \\ ${ }^{2}$ Interdisciplinary Graduate School of Engineering Sciences, Kyushu University, Japan \\ *Author to whom correspondence should be addressed, E-mail: ito@kyudai.jp
}

(Received July 31, 2014; accepted August 31, 2014)

\begin{abstract}
In the event of a severe nuclear, biological, or chemical (NBC) incident, perhaps related to terrorism or a nuclear power plant accident, rapid and effective decontamination procedures for the human body become critically important during on-site rescue operations. In this study, we propose a new decontamination system based on forced convection, called the wind decontamination system (WDCS). The fundamental performance of a WDCS prototype is evaluated by using computational fluid dynamics (CFD). The mass transfer characteristics of the WDCS air jets that act on the human body are quantitatively discussed, based on the CFD results.
\end{abstract}

Keywords: Computational Fluid Dynamics, Wind Decontamination System, Mass Transfer coefficient

\section{Introduction}

The necessity of developing a prompt and effective decontamination system for the outer surface of the human body has been brought into prominence by the severe incident at Fukushima Daiichi nuclear power plant in 2011. From the perspective of on-site rescue at the scene of a disaster, wet and dry decontamination processes are both regarded as universally applicable and basic countermeasures (Okumura T., 1998a and 1998b, Bronstein and Currance, 1994), especially in a chemical accident scenario involving gaseous or liquid contaminants. However, both wet and dry decontamination processes have limitations. A water-based decontamination procedure has an advantage in decontamination efficiency, but it is difficult to provide privacy to victims during the decontamination process because of the necessity of undressing. Furthermore, it is also difficult to set up the decontamination device quickly because of the limitations of hot-water preparation and on-site requirements of the water-pool. In a severe disaster scenario where hundreds of victims are exposed to hazardous contaminants, an effective and rapid decontamination method is required that can respond rapidly while also reducing the feeling of panic among the victims.

The primary objective of this study is to develop a novel decontamination procedure that uses forced convective flow, called the wind decontamination system (WDCS). The operating principle of the WDCS is similar to that of an industrial air-shower system. Although industrial air-shower systems have been widely adopted in factories and cleanrooms, a quantitative and qualitative method to evaluate their decontamination efficiency has not yet been fully discussed (Austin, 1970, $\mathrm{Li}$ and Ito, 2012, $\mathrm{Li}$ and Ito, 2014). In general, such a system has a conservative design, in consideration of the safety rate. From this background, the purpose of this

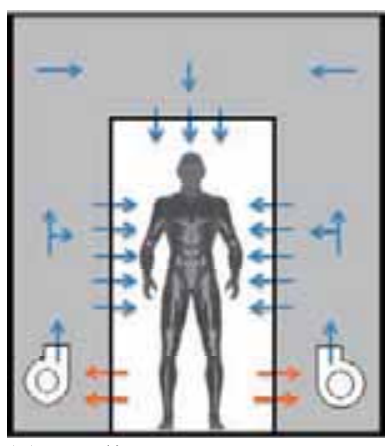

(a) Outline
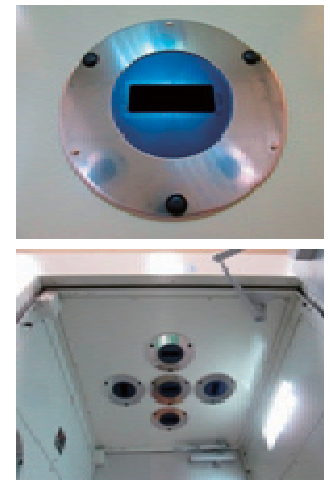

(c) Supply nozzles

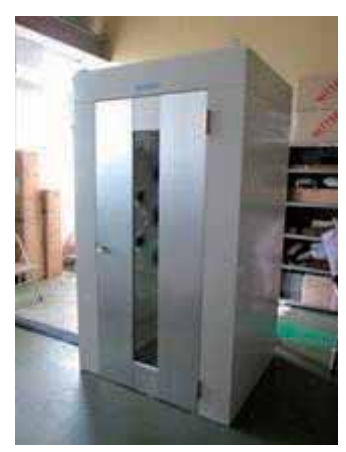

(b) Exterior Photo
Fig. 1. Exterior and interior spaces of the WDCS prototype. 
study is to discuss an optimized design method for a WDCS and an index of decontamination efficiency for a WDCS.

In previous research, we have evaluated the decontamination performance of an industrial air-shower system by experiment and computational fluid dynamics (CFD), and discussed the design of a WDCS prototype (Li and Ito, 2014). Following from this research, the purpose of this study is to conduct CFD simulations in accordance with experimental scenarios that target the detailed geometry of a WDCS, and to provide additional fundamental information applicable to the design of a WDCS. In particular, the mass transfer from the human body surface caused by a WDCS prototype is discussed as a fundamental index for the evaluation of the decontamination efficiency, based on the CFD results.

\section{WDCS prototype}

Figure 1 shows the outline of the WDCS prototype. The entry and exit doors are designed for rapid, one-way handling for in-order treatment of large numbers of casualties. There are a total of 21 supply nozzles placed on the side walls and ceiling. Each nozzle (detailed in Figure 1(c)) has a rectangular opening of area $1700 \mathrm{~mm}^{2}$, and can oscillate along the shorter axis at $2.0 \mathrm{~Hz}$, causing periodic fluctuation of flow jet direction. The 5 nozzles that are fixed on the ceiling are used to generate a uniform vertical flow from the top to bottom, in order to prevent recirculation of the contaminant. A total of 16 nozzles are installed on the side walls (Figure 1(d)), to ensure the purging of the contaminant from the local dead zones of the human body. The maximum airflow rate was $25 \mathrm{~m}^{3} / \mathrm{min}\left(1500 \mathrm{~m}^{3} / \mathrm{h}\right)$. Under this condition, the average inlet supply velocity of each nozzle is $12 \mathrm{~m} / \mathrm{s}$.

We have previously reported the results regarding the performance evaluation of an industrial air-shower system in removal of gaseous and liquid contaminants from the human body surface. With the objective of a portable decontamination operation, the WDCS prototype in this study is smaller and lighter than the industrial air-shower system previously investigated (Li and Ito, 2014). The airflow rate is also approximately reduced by half, with each nozzle having an equal flow. In addition, the self-induced oscillating jet from the flip-flop nozzle was adopted in the WDCS prototype, in order to increase the decontamination performance. The experimental results for fundamental decontamination efficiency have been reported in previous papers ( $\mathrm{Li}$ et al., 2013, Li and Ito, 2014).

\section{Outline of CFD simulation}

\subsection{Numerical and boundary conditions}

In this study, a CFD simulation was conducted to investigate the performance of a WDCS prototype. Figure 2 shows the outline of target space for numerical

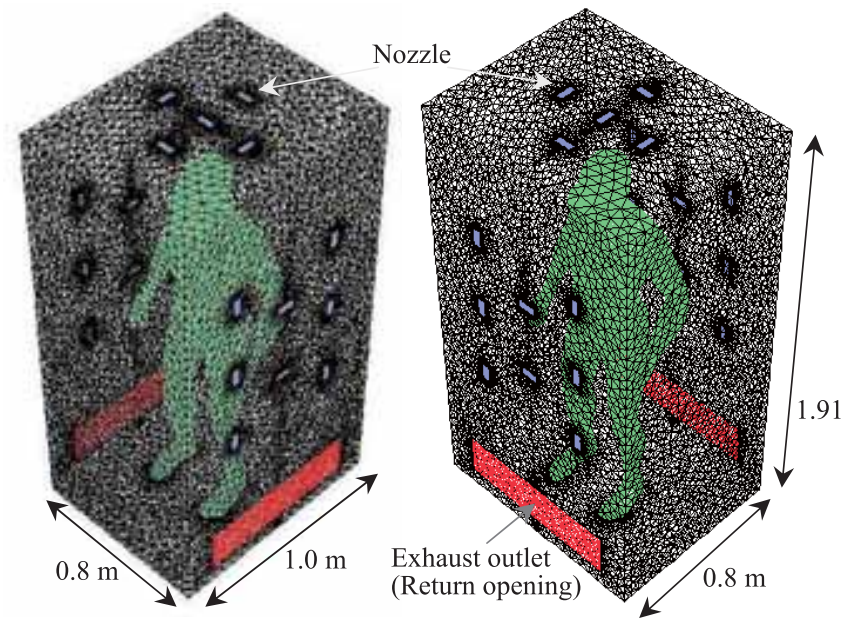

(a) Cross wind condition

(b) Facing wind condition Fig. 2. Numerical Analysis Domains

Table 1. Numerical and boundary conditions.

\begin{tabular}{l|l}
\hline Turbulence Model & SST k- $\omega$ model (3-D. calc.) \\
\hline Algorithm & SIMPLE (Steady and Unsteady) \\
\hline Scheme & Convection : QUICK \\
\hline \multirow{3}{*}{ Inflow boundary } & $\begin{array}{l}\text { Area of inlet }: 1700 \mathrm{~mm}^{2} \\
\text { Total air flow rate: } 25 \mathrm{~m}^{3} / \mathrm{min} \\
\text { Velocity magnitude }: 12 \mathrm{~m} / \mathrm{s}\end{array}$ \\
\hline \multirow{3}{*}{ Inflow direction } & $\begin{array}{l}\text { Steady: Perpendicular to wall } \\
\text { Oscillating: } 2.0 \mathrm{~Hz} \text { vibration } \\
\text { Turbulent Intensity: } 10,30 \text { and } 50 \%\end{array}$ \\
\hline Outflow boundary & $U_{\text {out }}=k_{\text {out }}=\varepsilon_{\text {out }}=$ Free slip \\
\hline Wall treatment & Velocity : No slip, $k_{\text {wall }}:$ No slip \\
(incl. human model) & Scalar (temp.): gradient zero $(\partial \mathrm{T} / \partial \mathrm{x}=0)$ \\
\hline
\end{tabular}

Table 2. Cases analyzed.

\begin{tabular}{|c|c|c|c|}
\hline Cases & $\begin{array}{l}\text { Wind direction } \\
\text { (relative position) }\end{array}$ & Air supply direction & $T I[\%]$ \\
\hline Case C-S & \multirow{4}{*}{ Cross wind } & (A) Steady & 10 \\
\hline Case C-O2 & & \multirow{3}{*}{ (C) Oscillating } & 10 \\
\hline Case C-O3 & & & 30 \\
\hline Case C-O4 & & & 50 \\
\hline Case F-S & \multirow{4}{*}{ Facing wind } & (A) Steady & 10 \\
\hline Case F-O2 & & \multirow{3}{*}{ (C) Oscillating } & 10 \\
\hline Case F-O3 & & & 30 \\
\hline Case F-O4 & & & 50 \\
\hline
\end{tabular}

simulation with a virtual manikin arranged in the center of the room (Ito and Hotta, 2006, Li and Ito, 2013). The triangular surface mesh reproduced the complex geometry of the human body shape. Prism cells were used to solve the boundary layer around the body. A minimum of four continuous layers of prism cells were allocated, with equal heights of less than $1.0 \mathrm{~mm}$. The wall units $\left(y^{+}\right)$that express the dimensionless normal distance from the surface approximately met the requirement of 1.0 over the whole surface of the body.

Two different wind conditions are considered: (1) The body facing the door (cross wind), with $(x, y, z)$ dimensions of $(0.8 \mathrm{~m}, 1.91 \mathrm{~m}, 1.0 \mathrm{~m})$, and (2) the body facing the wall (facing wind), with dimensions of $(1.0 \mathrm{~m}$, 
$1.91 \mathrm{~m}, 0.8 \mathrm{~m})$. The virtual manikin is representative of realistic human body proportions for an adult male.

The numerical and boundary conditions are listed in Table 1. The total airflow rate follows the performance of the WDCS prototype and is set to $25 \mathrm{~m}^{3} / \mathrm{min}\left(1500 \mathrm{~m}^{3} / \mathrm{h}\right)$. Correspondingly, the velocity magnitude of each supply inlet (nozzle) in the CFD simulation is $12 \mathrm{~m} / \mathrm{s}$. In view of the strong wind conditions, i.e., in excess of $10 \mathrm{~m} / \mathrm{s}$, the SST $k-\omega$ model was employed in CFD simulation (Menter et al., 2003). The SIMPLE algorithm was used with the QUICK scheme for the convective terms, and a second-order central difference scheme was used for the others. In addition, the turbulence intensity is set to either $10 \%, 30 \%$ and $50 \%$. The inlet air temperature $T_{\text {air }}$ and the skin surface temperature $T_{s k}$ are set at the fixed values of $T_{\text {air }}=293 \mathrm{~K}$ and $T_{s k}=307 \mathrm{~K}$. Detailed information is listed in Table 1. In this CFD simulation, the body was assumed to be unclothed.

\subsection{Cases analyzed by CFD simulation}

The cases analyzed by CFD simulation are listed in Table 2. Here, both steady-state (nozzles perpendicular to the wall, hereafter referred to as steady) and unsteady-state (oscillation at $2.0 \mathrm{~Hz}$, hereafter referred to as oscillating) simulations are carried out. Under the oscillating conditions, a time period of $10 \mathrm{~s}$ was simulated. Furthermore, in order to investigate the removal efficiency of the contaminant from the human body, we analyze the distribution of the convective heat transfer coefficient $\alpha_{c}$ around the body. The mass transfer coefficient can be estimated by assuming the Lewis analogy between heat transfer and mass transfer, and hence the analysis results for the convective heat transfer coefficient can provide fundamental information about the contaminant removal performance, as a first approximation to the parameters that influence a WDCS design.

The convective heat transfer coefficient $\alpha_{c}\left[\mathrm{~W} / \mathrm{m}^{2} / \mathrm{K}\right]$ can be obtained from the following equation (Eq.1):

$$
\alpha_{c}=\frac{Q_{c}}{T_{s k}-T_{\text {air }}}
$$

Here, $Q_{c}\left[\mathrm{~W} / \mathrm{m}^{2}\right]$ denotes the convective heat flux. $T_{s k}$ and $T_{\text {air }}$ represent the skin surface temperature and inlet air temperature respectively. Because the entire wall boundaries were set as fixed temperatures, the analysis for radiative heat transfer was disregarded in this CFD simulation.

\section{Results of CFD simulations}

\subsection{Distribution of flow field}

The flow field distribution around the body for the cross wind cases are shown by $x-z$ (left) and $y-z$ (right) view sections in Figure 3. From the $y-z$ view sections, it can be seen that the region of low velocity is wider under the oscillating condition than it is under the steady

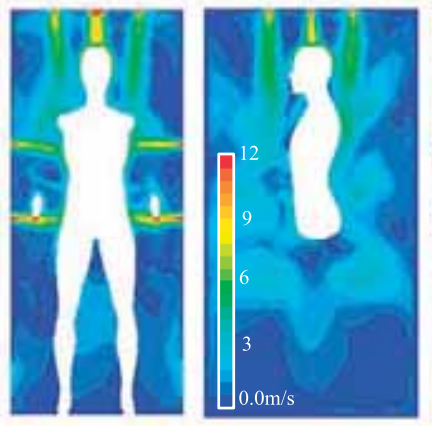

(a) Case C-S (Steady)

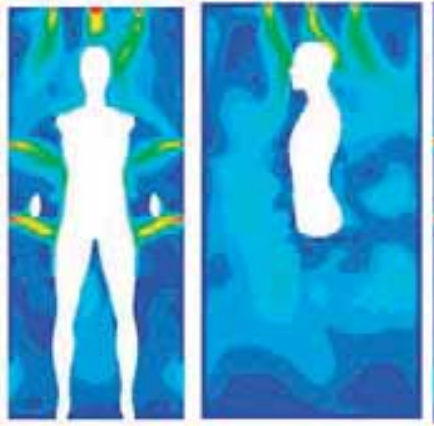

(c) Case C-O3 (Oscillating)

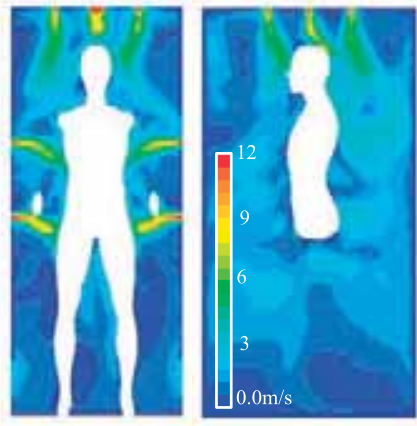

(b) Case C-O2 (Oscillating)

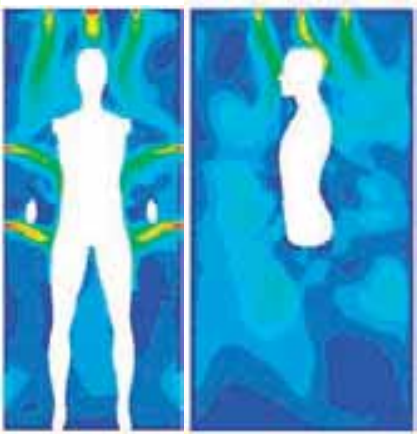

(d) Case C-O4 (Oscillating)
Fig. 3. Flow field distributions with a cross wind (velocity magnitude).

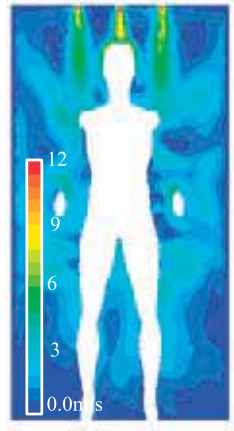

(a) Case F-S (Steady)

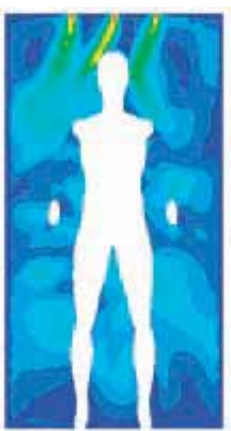

(c) Case F-O3 (Oscillating)
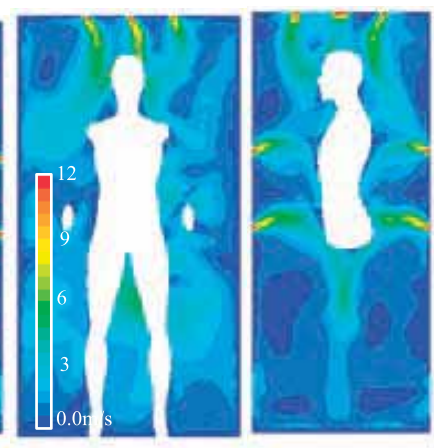

(b) Case F-O2 (Oscillating)

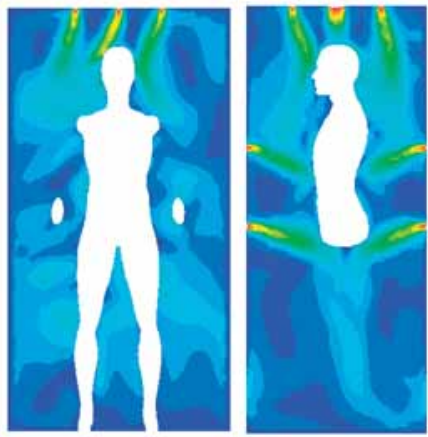

(d) Case F-O4 (Oscillating)
Fig. 4. Flow field distributions with a facing wind (velocity magnitude).

condition. In the steady condition, the air flow from the ceiling nozzles impinges directly against the head of the human body, and the air flow from the wall nozzles parts from the rear and back of the body. The measured velocity above the head was about $6 \mathrm{~m} / \mathrm{s}$. In the 
oscillating condition (fluctuating airflow at $2.0 \mathrm{~Hz}$ ), the velocity around the head in the unsteady air flow was also $6 \mathrm{~m} / \mathrm{s}$. For the nozzles on the side walls, the range of velocities around the body segments from the chest to the abdomen was smaller under the oscillating condition than it under the steady condition as shown in Figures 3(a) and (b). The range of velocities around the feet was larger in the oscillating condition than it was in the steady condition.

A lower velocity range around the human body was obtained in the oscillating condition compared to the steady condition. A relatively uniform and well-mixed flow field was observed under the oscillating condition.

Figure 4 shows the flow field distribution for the facing wind cases. Similar to the cross wind, the low velocity region was more widely distributed under the oscillating condition than under the steady condition. Additionally, the contributions of the nozzles on the ceiling and the walls to the head, chest, back, and the feet, were similar to those in cross wind.

\subsection{Convective heat transfer coefficient}

The distributions of the convective heat transfer coefficient $\alpha_{c}$ under cross wind are shown in Figure 5. For the oscillating conditions, time averages of values over a period of $10 \mathrm{~s}$ are shown in the figures. The distributions of $\alpha_{c}$ are very similar in the steady and oscillating conditions. Relatively large values of $\alpha_{c}$ appear at the top of the head, side of the body, and upper part of the thighs. The differences of $\alpha_{c}$ between body parts are found to be larger in the steady condition than in the oscillating condition.

Figure 6 shows distributions of $\alpha_{c}$ under the facing wind. Similar to the result under cross wind, the distributions of $\alpha_{c}$ are nearly the same in the steady condition and the oscillating condition. Relatively large values of $\alpha_{c}$ are found on the front of the abdomen, back, back of pelvis, and thighs.

The average values of the convective heat transfer coefficient $\alpha_{c}\left[\mathrm{~W} / \mathrm{m}^{2} / \mathrm{K}\right]$ and its standard deviations $\sigma$ are listed in Tables 3 and 4, for each body segment. The $\alpha_{c}$ values were relatively large in the steady condition compared to those in the oscillating condition, for almost all body segments. The relatively high velocity jets from nozzles were impinged against the human body in case of the steady condition and the convective heat transfer coefficients $\alpha_{c}$ were greatly evaluated in the parts. However, the standard deviations $\sigma$ were smaller in the oscillating condition. The periodically oscillating jets from the supply nozzles caused a relatively homogeneous distribution of $\alpha_{c}$ on the surface of the body.

The two different wind directions interacting with the human body were set up and analyzed by CFD simulations, and significant differences exist in the results obtained under each of these two wind directions. Especially, significant differences of flow pattern around human body and also the $\alpha_{c}$ distributions on the human

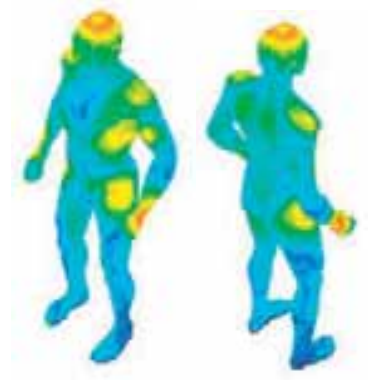

(a) Case C-S (Steady)

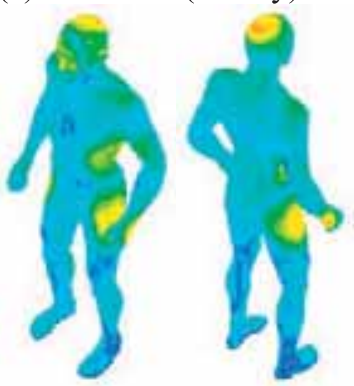

(c) Case C-O3 (Oscillating)

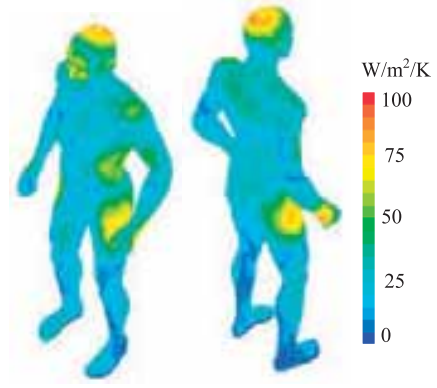

(b) Case C-O2 (Oscillating)

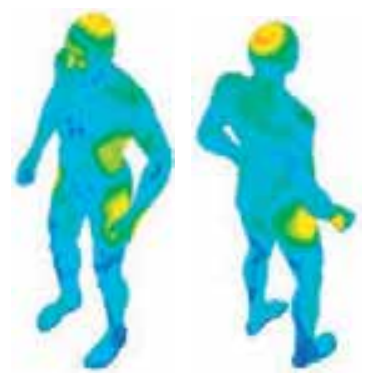

(d) Case C-O4 (Oscillating)
Fig. 5. Convective heat transfer coefficient $\alpha_{c}$ distributions with a cross wind.

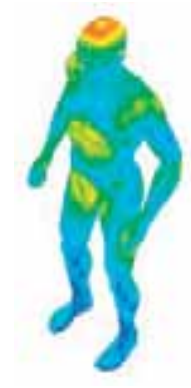

(a) Case F-S (Steady)

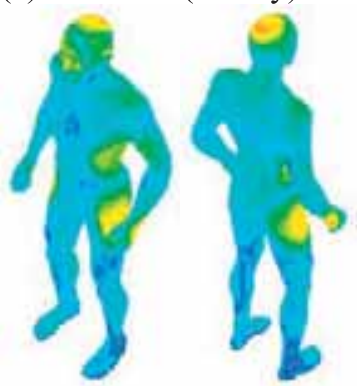

(c) Case F-O3 (Oscillating)

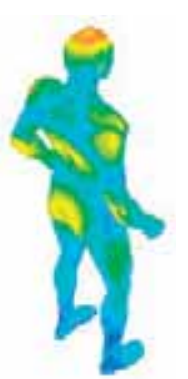

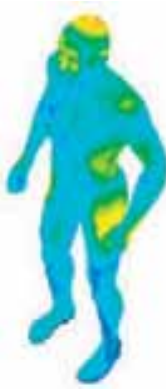

(b) Case F-O2 (Oscillating)

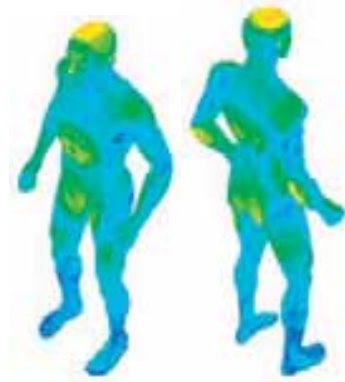

(d) Case F-O4 (Oscillating)
Fig. 6. Convective heat transfer coefficient $\alpha_{c}$ distributions with a facing wind.

body surfaces were observed in the two different wind directions. However, it is seen that the impact of the wind direction on the area-averaged convective heat transfer coefficient $\alpha_{c}$ for whole body is small in both two cases (steady and oscillating conditions) as shown in Tables 3 and 4.

In a comparison of the different oscillating conditions, the change of the turbulent intensity $T I$ of the air supplied by the nozzles $(T I=10 \%, 30 \%$, and $50 \%)$ had no definite impact on the estimated results of average $\alpha_{c}$. 
In the vicinity of supply nozzle, the velocity gradient of supplied jet and surrounding air was huge and turbulent kinetic energy was generated in proportion to the large velocity gradients. This is one of the causes of no-observed impact of $T I$ setting as supply inlet boundary condition of the nozzles.

\section{Conclusions}

The concept of a wind decontamination system (WDCS) is a novel decontamination method that is expected to substitute for dry and wet decontamination procedures.

In this study, we provided additional information about the flow pattern inside the WDCS, and the convective heat transfer characteristics on the human body surface were calculated by CFD simulation.

From the results of flow field and convective heat transfer coefficient, it was confirmed that the oscillation of the inlet air supply jet direction may contribute to an increase in the air-mixing in a WDCS, and increase the uniformity of convective heat transfer coefficients on the human body surfaces. By conducting the CFD simulation with two wind conditions (steady and oscillating conditions), it was found that the differences of the convective heat transfer coefficients between body segments are smaller in the oscillating condition than they are in the steady condition.

There is little previous research that quantitatively clarified the convective heat (and/or mass) transfer phenomena on the human body surface that occur either in an industrial air-shower system or in a WDCS. The CFD results regarding the distributions of the convective heat transfer coefficient $\alpha_{c}$ on the body surface are useful and valuable for optimizing the design of a WDCS.

\section{Acknowledgements}

The authors would like to express their sincere gratitude to Dr. Lim Eunsu and Mr. Takahiro Yamashita for their kind support and beneficial discussions on this research project.

\section{References}

1) ANSYS Fluent 12.1 Theory Guide, (2009).

2) P. R. Austin, Design and Operation of Clean Rooms, Business News Pub. Co. (1970).

3) A. C. Bronstein, P. L. Currance, Emergency Care for Hazardous Materials Exposure, Second ed., St. Louis, MO: Mosby Lifeline (1994).

4) K. Ito, T. Hotta, "Development of virtual manikins and its grid library for CFD analysis", Transactions of SHASE (The Society of Heating, Air-Conditioning and Sanitary
Table 3. Average $\alpha_{c}\left[\mathrm{~W} / \mathrm{m}^{2} / \mathrm{K}\right]$ on each body segment (Cross wind condition).

\begin{tabular}{|c|c|c|c|c|}
\hline \multirow{2}{*}{ Segment } & \multicolumn{2}{|c|}{ (A) Steady } & \multicolumn{2}{|c|}{ (B) Oscillating $T I=10 \%$} \\
\hline & $\alpha_{c}$ & $\sigma(\mathrm{STD})$ & $\alpha_{c}$ & $\sigma(\mathrm{STD})$ \\
\hline Neck & 39.875 & 17.477 & 34.771 & 17.375 \\
\hline Face & 44.010 & 17.533 & 33.169 & 15.362 \\
\hline Back & 32.128 & 9.857 & 25.127 & 8.368 \\
\hline Chest & 42.248 & 18.779 & 33.492 & 16.433 \\
\hline Pelvis & 36.120 & 17.535 & 31.606 & 15.765 \\
\hline Left Shoulder & 35.370 & 15.176 & 29.783 & 12.309 \\
\hline Right Shoulder & 34.018 & 16.147 & 27.837 & 11.340 \\
\hline Left Arm & 32.172 & 21.698 & 30.116 & 12.404 \\
\hline Right Arm & 30.793 & 21.238 & 31.022 & 14.890 \\
\hline Left Hand & 38.366 & 21.205 & 27.994 & 14.931 \\
\hline Right Hand & 39.683 & 20.540 & 30.666 & 17.047 \\
\hline Left Thigh & 22.795 & 10.323 & 21.681 & 9.998 \\
\hline Right Thigh & 21.999 & 9.908 & 21.486 & 9.790 \\
\hline Left Leg & 15.592 & 6.028 & 15.781 & 7.167 \\
\hline Right Leg & 15.657 & 6.061 & 16.362 & 6.630 \\
\hline Left Foot & 12.409 & 6.394 & 15.156 & 8.584 \\
\hline Right Foot & 11.773 & 6.608 & 15.408 & 8.383 \\
\hline Whole body & 30.105 & 18.778 & 26.374 & 15.557 \\
\hline
\end{tabular}

Table 4. Average $\alpha_{c}\left[\mathrm{~W} / \mathrm{m}^{2} / \mathrm{K}\right]$ on each body segment (Facing wind condition).

\begin{tabular}{|c|c|c|c|c|}
\hline \multirow{2}{*}{ Segment } & \multicolumn{2}{|c|}{ (A) Steady } & \multicolumn{2}{|c|}{ (B) Oscillating $T I=10 \%$} \\
\hline & $\alpha_{c}$ & $\sigma(\mathrm{STD})$ & $\alpha_{c}$ & $\sigma(\mathrm{STD})$ \\
\hline Neck & 37.436 & 16.551 & 31.696 & 15.378 \\
\hline Face & 41.865 & 18.183 & 36.684 & 16.295 \\
\hline Back & 38.980 & 15.135 & 31.844 & 12.248 \\
\hline Chest & 36.156 & 14.415 & 30.280 & 13.277 \\
\hline Pelvis & 36.452 & 17.640 & 31.911 & 14.674 \\
\hline Left Shoulder & 31.995 & 14.141 & 27.285 & 11.267 \\
\hline Right Shoulder & 36.371 & 15.610 & 28.388 & 11.584 \\
\hline Left Arm & 43.569 & 17.675 & 35.631 & 14.988 \\
\hline Right Arm & 42.952 & 16.567 & 32.517 & 13.731 \\
\hline Left Hand & 35.607 & 15.535 & 27.704 & 11.923 \\
\hline Right Hand & 31.531 & 15.061 & 29.754 & 13.282 \\
\hline Left Thigh & 31.136 & 13.416 & 28.421 & 9.601 \\
\hline Right Thigh & 29.926 & 12.183 & 28.212 & 10.921 \\
\hline Left Leg & 15.632 & 7.229 & 13.233 & 5.159 \\
\hline Right Leg & 15.543 & 6.967 & 13.734 & 5.536 \\
\hline Left Foot & 15.357 & 7.546 & 14.764 & 6.682 \\
\hline Right Foot & 13.568 & 7.451 & 14.710 & 7.537 \\
\hline Whole body & 32.036 & 17.326 & 27.525 & 14.952 \\
\hline
\end{tabular}

Engineers of Japan), 113, 27-34 (2006) .(In Japanese)

5) C. Li, K. Ito, "Performance evaluation of industrial air-shower system in removal of gas- and liquid-phase 
contaminants from human body", Evergreen-Joint Journal of Novel Carbon Resource Sciences \& Green Asia Strategy, 1(1), 40-47 (2014).

6) C. Li, K. Ito, "Numerical and experimental estimation of convective heat transfer coefficient of human body under strong forced convective flow", Journal of Wind Engineering \& Industrial Aerodynamics, 126, 107-117 (2014).

7) C. Li, K. Ito, "Numerical analysis of convective heat and mass transfer around human body under strong wind", International Journal of High-Rise Buildings, 1(2), 107-116 (2012).

8) Y. Li, S. Someya, T. Koso, S. Aramaki, K. Okamoto, "Characterization of periodic flow structure in a small-scale feedback fluidic oscillator under low-Reynolds-number water flow", Flow Measurement and Instrumentation., 33, 179-187 (2013).

9) F. R. Menter, M. Kuntz, R. Langtry, "Ten years of Industrial experience with the SST turbulence model", in Turbulence, Heat and Mass Transfer 4, eds by $\mathrm{K}$. Hanjalic, Y. Nagano, M. Tummers, 625-632 (2003).

10) T. Okumura, K. Suzuki, A. Fukuda, A. Kohama, N. Takasu, S. Ishimatsu, S. Hinohara, "The Tokyo subway sarin attack: disaster management, part 2: hospital response", Acad. Emerg. Med., 5, 618-624 (1998).

11) T. Okumura, K. Suzuki, A. Fukuda, A. Kohama, N. Takasu, S. Ishimatsu, S. Hinohara, "The Tokyo subway sarin attack: disaster management, part 3: national and international response", Acad. Emerg. Med., 5, 625-628 (1998). 